\title{
Cost Savings of Reduced Constipation Rates Attributed to Increased Dietary Fibre Intakes in Europe: A Decision-Analytic Model
}

\author{
Jordana K. Schmier ${ }^{1}$, Vanessa Perez ${ }^{2}$, Susan Cloran ${ }^{3}$, Carolyn Hulme-Lowe ${ }^{1}$ and \\ Kathryn O'Sullivan ${ }^{4, *}$
}

${ }^{1}$ Exponent Inc., 1800 Diagonal Road, Suite 500, Alexandria, VA 22314, USA

${ }^{2}$ Exponent Inc., 525 W. Monroe Street, Suite 1050, Chicago, IL 60661, USA

${ }^{3}$ Nutrition Department, Kellogg Europe Trading Limited, Lakeshore Drive, Airside Business Park, Swords, Dublin, Ireland

${ }^{4}$ Dr. O'Sullivan Nutrition Consulting, Ltd., 119 Moss Lane, Timperley, WA15 6JG, Cheshire, UK

\begin{abstract}
Mounting evidence shows that functional constipation contributes to increased healthcare utilization, impairment in quality of life, and lost work productivity. Among those with functional constipation, relatively small dietary changes may alleviate symptoms and result in considerable constipation-related healthcare cost savings. The study objective was to estimate the economic impact of increased dietary fibre consumption on direct medical costs associated with constipation from a payer perspective. A decision-analytic spreadsheet model was created to perform the analysis. Literature searches identified sources for input parameters, including prevalence of functional constipation, dietary fibre intakes, proportion of the population meeting recommended intakes, and the percentage that would be expected to benefit from increased dietary fibre consumption. The model assumes that $25 \%$ of adults make no change in fibre intake, $25 \%$ increase intake by $3 \mathrm{~g} /$ day, $15 \%$ increase intake by $4 \mathrm{~g} /$ day, $25 \%$ increase intake by $5 \mathrm{~g} /$ day, and $10 \%$ increase intake by $11 \mathrm{~g} /$ day. A dose-response analysis of published data was conducted to estimate the percent reduction in constipation prevalence per $1 \mathrm{~g} /$ day increase in dietary fibre intake. Annual direct medical costs for constipation were derived from the literature and updated to 2014. Sensitivity analyses explored robustness of the model. Under base case assumptions, annual cost savings were estimated at $£ 127,037,383$ in the United Kingdom, €8,791,992 / £7,244,513 in Ireland, and $€ 121,699,804$ in Spain. Increasing dietary fibre consumption is associated with considerable cost savings, with these estimates being conservative given the exclusion of lost productivity costs in the model.
\end{abstract}

Keywords: Constipation, public health, prevention, costs and cost analysis, dietary fibre.

\section{INTRODUCTION}

Functional constipation, also known as chronic idiopathic constipation, is a bowel disorder that can cause considerable discomfort and is characterized by multiple symptoms, including defecation accompanied by straining, hard stools, incomplete evacuation, a sensation of anorectal obstruction, manual manoeuvers, and less than three stools per week [1]. The prevalence of functional constipation in the general population of Europe ranges from $5 \%$ to $35 \%$, with a median value (16.6\%) comparable to that of the worldwide population (16\%) [2-4]. This variation in prevalence estimates is due, in part, to the methods and criteria used for case ascertainment (e.g., selfreport vs. clinical evaluation) as well as changing case definitions over time. In addition to documented prevalence based on clinical diagnostic criteria, there may be substantial additional burden associated with constipation identified by self-report or not meeting clinical criteria that is excluded from published

*Address correspondence to this author at Nutrition Department, Kellogg Europe Trading Ltd, Lakeshore Drive, Airside Business Park, Swords, Dublin, Ireland. Tel: 00441618692000. Email: Sue.Cloran@Kellogg.com prevalence estimates; thus the impact of constipation may affect many more people than those identified by formal methods [5]. Risk factors for functional constipation include older age, sex (women are disproportionately affected), socioeconomic position, pregnancy, a sedentary lifestyle, and diet, among others [3]. Although functional constipation is rarely lifethreatening and easily treatable, if left untreated this condition can result in serious bowel malfunction (e.g., faecal impaction, perforation of the intestine) resulting in a reduced quality of life and increased healthcare utilization. In fact, accumulating evidence shows that functional constipation is a significant factor in health care utilization, impairment in quality of life, and lost work productivity [6-12].

While some cases of constipation may indicate a more serious complaint, for many, functional constipation could be relieved by simple dietary management. Dietary modification presents a safe, effective, and economical option for improving gut health that can be a natural alternative to pharmacological treatment $[13,14]$. Dietary fibre has been highlighted as a nutrient of concern and deficiency is common in many European countries. For 
example $80 \%$ of UK diets are fibre deficient [13, 14]. Simple, yet effective dietary modifications such as increasing daily fibre intake via foods, like whole grain cereals, fruit and vegetables, potatoes, and nuts and seeds, may also have major economic implications with respect to health care utilization and productivity. In fact, a recent study using United States data reported that annual savings in direct medical costs associated with the treatment of functional constipation could exceed $\$ 12$ billion (in 2013 dollars) with an incremental increase in the consumption of dietary fibre [15]. No such evaluation has been conducted in Europe, where current dietary fibre intakes for adults reportedly range from $18 \mathrm{~g} /$ day to $29.7 \mathrm{~g} /$ day, on average, in men, and from $15.7 \mathrm{~g} / \mathrm{d}$ to $21.7 \mathrm{~g} /$ day, on average, in women, across the 22 countries included in the survey [16]. The current fibre recommendation by the European Food Safety Authority's Panel on Dietetic Products, Nutrition and Allergies for adults with normal bowel movement is $25 \mathrm{~g} /$ day [16].

The objective of this study was to identify potential cost savings in terms of direct medical expenditures (i.e., medical encounters and prescriptions) associated with increased intake of dietary fibre in the United Kingdom, Ireland, and Spain. The model presented was designed to be flexible and capable of exploring a wide range of inputs. A base case as well as multiple sensitivity analyses were evaluated and are discussed.

\section{METHODS}

A decision-analytic economic model requires a number of different types of input in order to populate all the input parameters. First, in this case, estimates about the size of the population are needed. These can be identified from standard sources. Second, clinical or epidemiological inputs are required to identify the proportion of people who might benefit from an intervention. For example, in this case it is necessary to understand the proportion of the population that has constipation as well as the proportion that has suboptimal dietary fibre intake. These types of data typically are derived from peer-reviewed, published literature or national surveys. If pharmaceutical interventions were being compared, data might be derived from clinical trials and/or meta-analyses of published literature. Finally, the third major type of input for this type of model is the cost of illness, in this case, constipation. These costs are often available in the literature or can be collected prospectively or built-up from expected resource utilization rates multiplied by the cost per unit. Care needs to be taken that estimates are relevant in terms of perspective (eg hospital costs versus the total cost of care) and that currency is adjusted to the same fiscal year.

As a model with so many types of inputs from various sources is subject to multiple sources of uncertainty, it is important to conduct sensitivity analyses to explore the influence of various model inputs and the extent to which each may affect the model's results. However, the use of published and/or validated sources is considered best practice $[17,18]$, and often preferred to primary data collection in that the findings tend to be more generalizable.

The decision-analytic model estimates the direct medical cost savings associated with constipation among adult men and women based on the following factors: (1) baseline dietary fibre consumption, specifically, the proportion of the population not meeting intake recommendations; (2) the prevalence of constipation among those not meeting dietary fibre intake recommendations; (3) the proportion of those likely to respond, in terms of alleviation of constipationassociated symptoms, to increased dietary fibre intakes; (4) the estimated decrease in constipation prevalence associated with each $1 \mathrm{~g} /$ day increase of dietary fibre intake; and (5) the expected change in dietary fibre intake. The medical costs for constipation prior to and following the hypothetical intervention (i.e., increased dietary fibre intake) are compared.

All inputs used for this model were extracted from the peer-reviewed literature and no original research involving human subjects was conducted; therefore, the study was not subject to institutional review board review and did not require written informed consent.

The model focuses on adults because while there appears to be substantial prevalence of constipation among young children, increasing dietary fibre intake as a first-line treatment is less common in the pediatric population $[2,19,20]$. Since there is minimal opportunity for a change in diet to affect constipation rates for this population, they have been excluded from the model.

\section{Identification and Definition of Input Parameters}

The spreadsheet model includes inputs from multiple sources. A full list of these sources and base case parameters are presented in Tables 1-3. Many of the input parameters were obtained directly from the peer-reviewed literature. As the tables demonstrate, default values were provided, but the user can vary the inputs within a specified range or add a value that is more specific or is outside of the range. 
Table 1: Input Parameters and Sources: United Kingdom

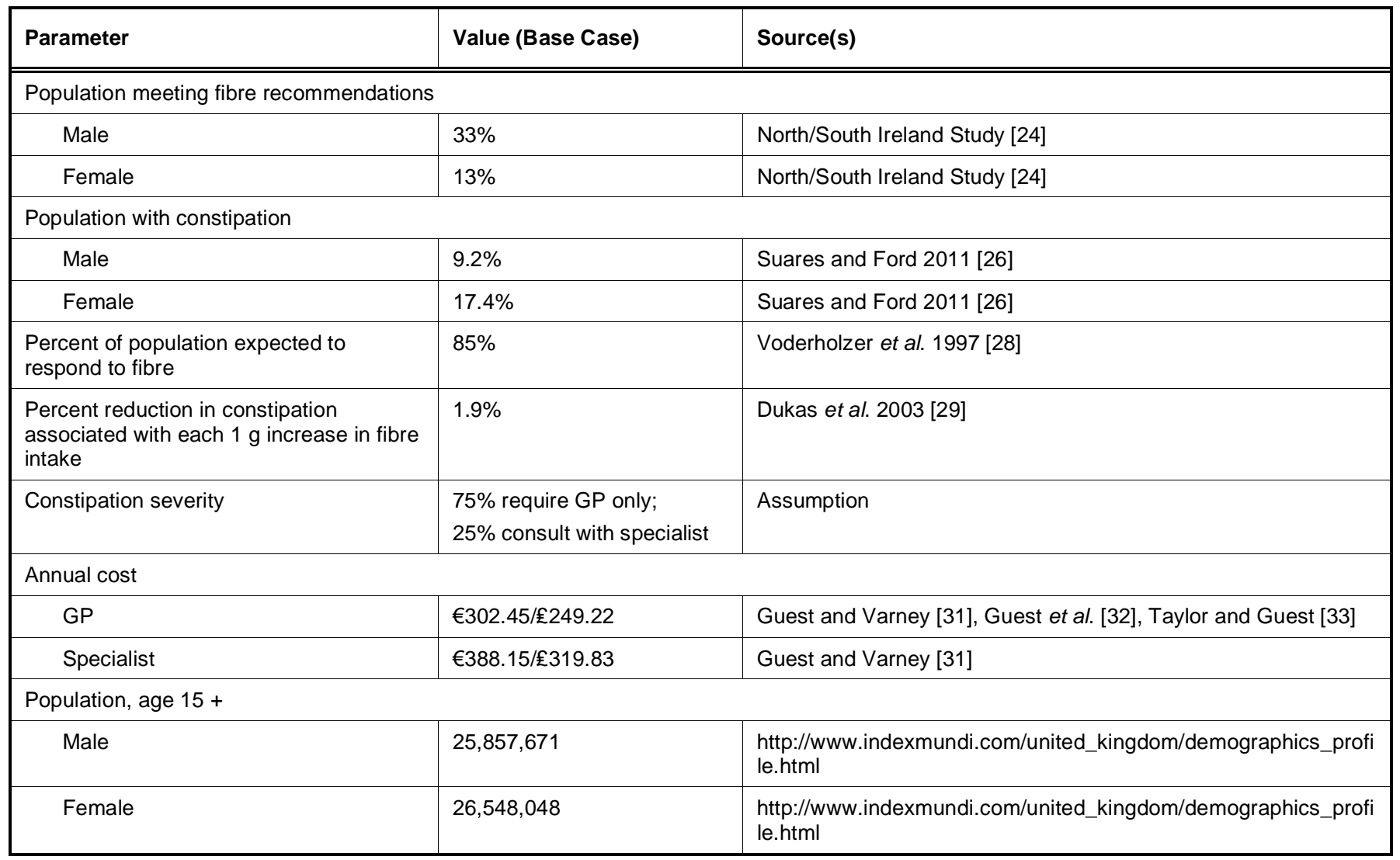

Table 2: Input Parameters and Sources: Ireland

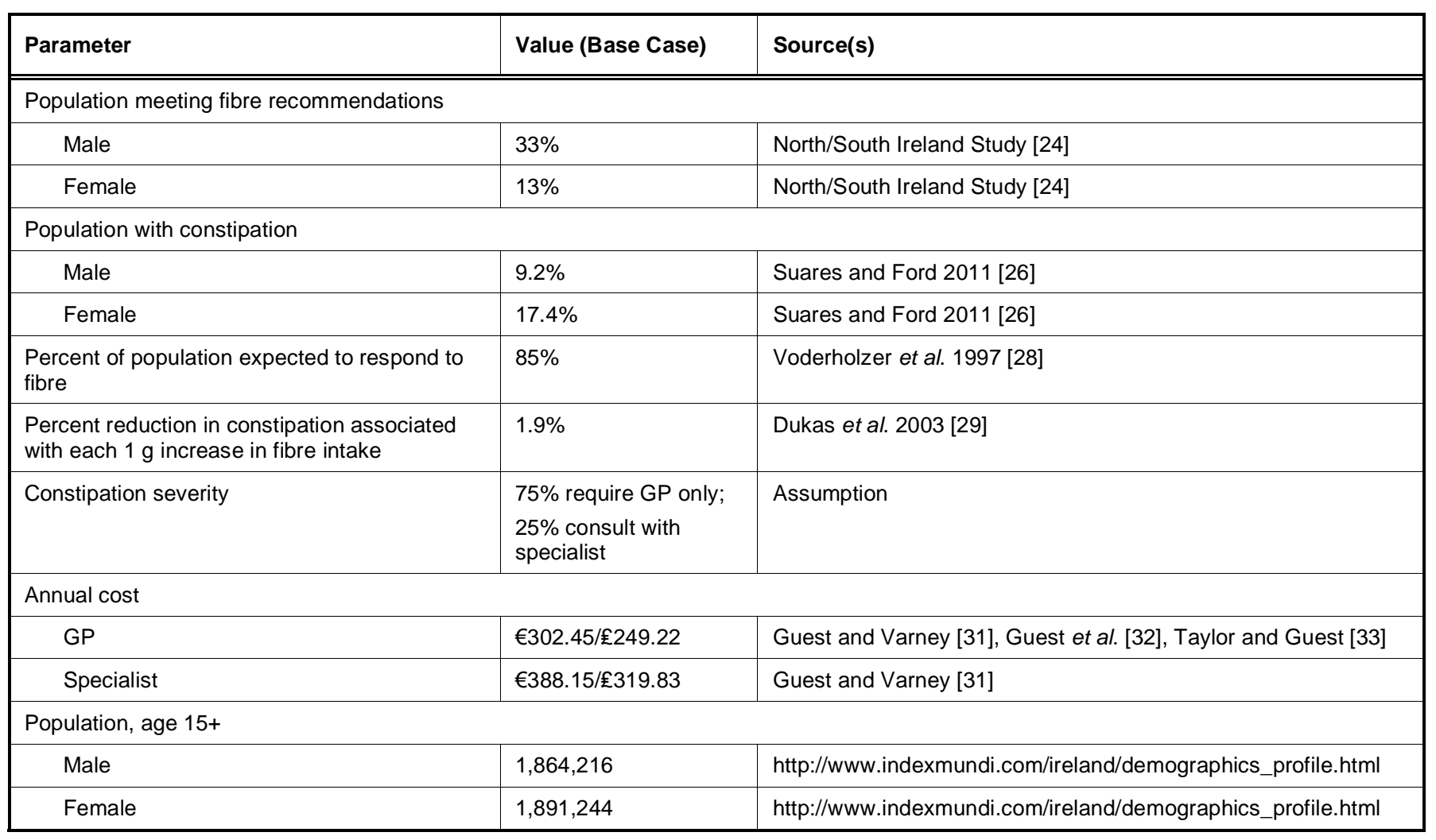


Table 3: Input Parameters and Sources: Spain

\begin{tabular}{|c|c|c|}
\hline Parameter & Value (Base Case) & Source(s) \\
\hline \multicolumn{3}{|l|}{ Population meeting fibre recommendations } \\
\hline Female & $3 \%$ & Evaluacion Nutricional de la Dieta Espanola [25] \\
\hline \multicolumn{3}{|l|}{ Population with constipation } \\
\hline Female & $22.0 \%$ & Garrigues et al. [27] \\
\hline $\begin{array}{l}\text { Percent of population expected to respond to } \\
\text { fibre }\end{array}$ & $85 \%$ & Voderholzer et al. 1997 [28] \\
\hline $\begin{array}{l}\text { Percent reduction in constipation associated } \\
\text { with each } 1 \mathrm{~g} \text { increase in fibre intake }\end{array}$ & $1.9 \%$ & Dukas et al. 2003 [29] \\
\hline GP & $€ 302.45 / £ 249.22$ & $\begin{array}{l}\text { Guest and Varney [31], Guest et al. [32], Taylor and Guest } \\
\text { [33] }\end{array}$ \\
\hline Specialist & $€ 388.15 / £ 319.83$ & Guest and Varney [31] \\
\hline \multicolumn{3}{|l|}{ Population, age $15+$} \\
\hline Male & $19,734,451$ & http://www.indexmundi.com/spain/demographics_profile.html \\
\hline Female & $20,457,816$ & http://www.indexmundi.com/spain/demographics_profile.html \\
\hline
\end{tabular}

Population data were taken from Index Mundi [2123]. Values for baseline dietary fibre intakes were derived from publicly available estimates [24, 25]. For example, the base case of the model assumes that $33 \%$ of the adult male population and $13 \%$ of the adult female population meet dietary fibre recommendations in the United Kingdom and Ireland [24]. In Spain, as few as $3 \%$ (women) to $6 \%$ (men) of adults meet Spanish dietary fibre recommendations [25].

Estimates of constipation prevalence based on Rome III diagnostic criteria whenever possible, were identified from a systematic review of the epidemiologic literature available in PubMed through March 2014. For the United Kingdom and Ireland, it was assumed that $9.2 \%$ of men and $17.4 \%$ of women have functional constipation [26], while for Spain it was assumed that $5.5 \%$ of men and $22.0 \%$ of women have functional constipation [27].

The proportion of adults with functional constipation who would be expected to respond to dietary fibre is set at $85 \%$ in the base case [28]. This accounts for the possibility that some patients might not have functional constipation, that is, constipation that would be expected to respond to increased fibre intake; some proportion may be misdiagnosed and have IBS or another cause. Only one epidemiologic study provided sufficient data to estimate the percentage reduction in constipation prevalence associated with an increase in dietary fibre intake [29]; this study was conducted among women 36 to 61 years of age in the Nurses' Health Study. The dose-response estimate generated from this study was used as the default value in the model for each country (i.e., for each $1 \mathrm{~g}$ increase in dietary fibre intake, the prevalence of constipation decreases by $1.9 \%)$.

A literature search was conducted to identify the costs of treatment for patients with functional constipation. Multiple studies were identified [30-33]. Given the absence of differential cost data for men versus women, the base case assumes that annual costs are equivalent for adults in the United Kingdom, Ireland, and Spain. Costs were inflated to 2014 values using price index information as reported by Eurostat (epp.eurostat.ec.europa.eu/), and subsequently converted to Euros or pounds using exchange rates as reported by the Oanda Corporation (www.oanda.com). Tables 1-3 present the sources for cost inputs for the country-specific models.

Important challenges in identifying costs are that most available studies are focused on opioid-induced 
constipation, are for patients with constipation predominant irritable bowel syndrome (IBS-C), or are for very specific populations (i.e., adults in long-term care or infants). Thus, although many peer-reviewed publications appear to be relevant based on title review alone, only a limited number of cost studies are available for our study purpose, that is, estimating the cost associated with treatment for functional constipation specifically. Of the studies reporting direct medical costs for functional constipation, they included costs associated with physician visits (either a general practitioner or a specialist), diagnostic tests, and pharmacologic treatment [31-33]. The publications that provided cost estimates also presented rates of success-that is, the lack of need for additional treatment at either 3- or 6-month intervals [31-33]. Treating each study individually, the model applied the proportion of successfully-treated patients at each time interval, thus if $20 \%$ of patients could discontinue treatment after 3 months, the remaining $80 \%$ would have the cost of constipation treatment applied for months $4-6$, while $20 \%$ would have no cost for the next quarter. Similarly, the same success rate was applied to the patients who required treatment for a second quarter. Of those patients, who represent $80 \%$ of the original population, $20 \%$ of those patients would be able to discontinue treatment in the next quarter and the remainder would require additional treatment (i.e., $80 \%$ of $80 \%$, or $64 \%$ of the original population at baseline). The annual costs for each study were then averaged to estimate the annual costs for patients with physician-diagnosed functional constipation.

A base case was created to reflect a plausible scenario given existing information. The base case is limited to the adult population (age 15 and older), and distributes the population as follows: $25 \%$ make no change in fibre intake, $25 \%$ increase daily fibre intake by $3 \mathrm{~g} /$ day, $15 \%$ increase daily fibre intake by $4 \mathrm{~g} /$ day, $25 \%$ increase daily fibre intake by $5 \mathrm{~g} /$ day, and $10 \%$ increase daily fibre intake by $11 \mathrm{~g} /$ day. An increase of as little as $3 \mathrm{~g} /$ day was included in accordance with evidence that suggests small changes in dietary fibre intake have been shown to produce measurable changes in digestive symptoms in the short-term [13]. The proportion of cases treated by general practitioners
(GP) versus specialists is an assumption. The base case assumes that $75 \%$ of adults who present for care are treated by a GP and the remainder present at a specialist. There is no evidence in the literature to inform this parameter, but guidelines for constipation typically suggest a treat-then-test approach [34], implying that primary care providers are an important first step in treatment [35]. These values can be modified by the user and were tested in sensitivity analyses.

For each input parameter, sensitivity analyses were conducted assuming a range of plausible values. The model is designed to allow the user to specify the distribution of the population based on the following categories: no additional dietary fibre, or an additional $3,4,5,6,7.5,8,9,10,11$, or $15 \mathrm{~g} /$ day of dietary fibre. A key sensitivity analysis case assumed that all adults with dietary fibre intake below recommended levels would increase their dietary fibre intakes by $11 \mathrm{~g} /$ day, a value that is consistent with the addition of a bowl of bran cereal to the diet daily. Actual intake amounts vary, with more men meeting daily intake requirements than women [24]. In addition, sensitivity analyses explored the results if all patients were successfully treated at three months (i.e., accrued no additional constipation treatment costs after three months) or if all required treatment for the entire 12-month period.

\section{RESULTS}

Country-specific results for the base case show that the annual cost savings were estimated at $£ 127,037,383$ in the United Kingdom, €8,791,992 / $£ 7,244,513$ in Ireland, and $€ 121,699,804$ in Spain (Table 4).

Univariate sensitivity analyses show that the largest change (increase) in cost savings corresponds to the scenario in which every adult increased daily fibre intake by $11 \mathrm{~g} /$ day (Table 5). For example, in the United Kingdom, this corresponds to a $197 \%$ increase from the base case results, or $£ 377.3$ million. Another influential parameter was the percent of population with functional constipation. Sensitivity analyses explored setting the proportion of men and women who report constipation to $5.5 \%$ and $22.0 \%$, respectively; these

Table 4: Results

\begin{tabular}{|l|l|l|l|}
\hline \multirow{2}{*}{ Key Parameters and Change(s) } & \multicolumn{2}{|l|}{ Annual Cost Reduction } & Spain \\
\cline { 2 - 4 } & United Kingdom & Ireland & $€ 121,699,804$ \\
\hline \hline $\begin{array}{l}\text { Base case: } 25 \% \text { of adults make no change, 25\% } \\
\text { increase } 3 \mathrm{~g} \text { daily, } 15 \% \text { increase } 4 \mathrm{~g} \text { daily, 25\% increase } \\
5 \mathrm{~g} \text { daily, } 10 \% \text { increase } 11 \mathrm{~g} \text { daily }\end{array}$ & $£ 127,037,383$ & $€ 8,791,992 /$ & \\
\hline
\end{tabular}


Table 5: Sensitivity Analysis: Change in Cost Reduction

\begin{tabular}{|l|l|l|l|}
\hline \multirow{2}{*}{ Key Parameters and /or Change(s) } & \multicolumn{2}{l|}{ Change in Annual Cost Reduction from Base Case } \\
\cline { 2 - 4 } & United Kingdom & Ireland & Spain \\
\hline \hline All adults 15 and older) add $11 \mathrm{~g}$ fibre to daily diet & $+197 \%$ & $+197 \%$ & $+197 \%$ \\
\hline $10 \%$ of adults meet fibre intake recommendations & $+17 \%$ & $+12 \%$ & $+1 \%$ \\
\hline $50 \%$ of adults meet fibre intake recommendations & $-35 \%$ & $-38 \%$ & $-9 \%$ \\
\hline $5 \%$ of adults have functional constipation & $-68 \%$ & $-60 \%$ & $-61 \%$ \\
\hline $25 \%$ of adults have functional constipation & $+44 \%$ & $+80 \%$ & $+78 \%$ \\
\hline $25 \%$ of adults are responsive to fibre increase & $-71 \%$ & $-71 \%$ & $-71 \%$ \\
\hline $100 \%$ of adults are responsive to fibre increase & $+18 \%$ & $+18 \%$ & $+18 \%$ \\
\hline $100 \%$ require GP care & $-18 \%$ & $-18 \%$ & $-78 \%$ \\
\hline $100 \%$ require specialist care & $+6 \%$ & $+6 \%$ & $+6 \%$ \\
\hline $100 \%$ require 12 months of treatment & $+73 \%$ & $+73 \%$ & $+73 \%$ \\
\hline $100 \%$ require 3 months of treatment & $-57 \%$ & $-57 \%$ & $-57 \%$ \\
\hline
\end{tabular}

${ }^{a} \mathrm{~A}$ lack of country-specific input information resulted in equivalent estimates across countries for some sensitivity analyses.

${ }^{\mathrm{b}}$ The percent change in cost reduction is associated with the proportion of the population that may benefit from additional fibre consumption given the parameter in question. For example, if only $10 \%$ of adults in the United Kingdom meet the recommended intake for fibre, as opposed to approximately $22 \%$ under the base case, the proportion of the population that may benefit from additional fibre intake increases; therefore, we see a $17 \%$ increase in the possible cost reduction.

values were the lowest prevalence found in the literature. Given the few studies and small difference in costs between GP and specialist care, assuming that all patients received care from one type of physician versus the other had little influence on the results. All results are presented in Table 5.

\section{Multivariate Sensitivity Analyses}

Extreme scenarios were explored with multivariate sensitivity analyses. A high-impact scenario, in which there was a large increase in fibre intake and a large proportion of the population with constipation who could respond to increased fibre, was assessed. This scenario estimates the constipation-related cost savings that would be realized with the worst baseline population health and the most substantial increase in fiber intake, thus maximizing the potential benefit of the dietary change. This high-impact scenario assumes an increased fibre intake of $11 \mathrm{~g} / \mathrm{day}$ to the diet for all adults, that only $5 \%$ of adults (applied to men and women) currently meet fibre intake recommendations, that $33 \%$ have functional constipation, that $100 \%$ are responsive to fibre increase, that every $1 \mathrm{~g}$ increase in intake results in a $3 \%$ decrease in constipation, and that $100 \%$ of adults require specialist care. To explore the limits of cost savings, this scenario also assumes that patients require ongoing treatment for the entire year. An extreme high-impact scenario like this resulted in cost savings of more than €3.6 billion / £3.0 billion in the United Kingdom (data not shown). In the other direction, an extreme low-impact scenario $(75 \%$ of adults meeting intake requirements, $75 \%$ do not change their diet, $25 \%$ increase their intake by $3 \mathrm{~g} /$ day, $1 \%$ have constipation, $25 \%$ are responsive to fibre, there is a $1 \%$ reduction in constipation for each gram of fibre, patients are treated in three months, and all treatment is by a GP) showed a cost savings in the United Kingdom of €31,959 / £26,334 (data not shown).

\section{DISCUSSION}

Significant proportions of the population throughout Europe do not eat enough fibre and as a result are at risk of developing functional constipation and associated symptoms of digestive discomfort [13, 14]. Increased dietary fibre consumption for adults with functional constipation is associated with a significant cost savings in the United Kingdom, Ireland, and Spain. The direct medical cost savings estimated across countries are likely conservative estimates due to the exclusion of children and lost productivity costs in the model.

Fibre is an essential part of a balanced diet. It is a collective term for a group of non digestible compounds found in plants which differ in their chemical structure and physical properties. They elicit a variety of physiological effects but share the ability to pass undigested into the large intestine [13, 14]. Wholegrains, fruits, vegetables, legumes and nuts are sources of fibre. Simple changes to dietary habits can have a big impact on fibre intakes. Promoting high fibre options of commonly eaten foods such as breads, breakfast cereals, and other grain based foods can be a simple strategy for improving fibre levels in the population. Foods can be labeled in Europe as "high in fibre" when they contain $6 \mathrm{~g}$ or more fibre per $100 \mathrm{~g}$ of food or "source of fibre" when they contain $3 \mathrm{~g}$ or more 
per $100 \mathrm{~g}$. Strategies to increase supply, availability and consumer demand of high fibre variants of commonlyconsumed foods could improve population intakes. The finding that a simple, realistic dietary change at the population level consisting of increased daily fibre intakes results in an economic benefit supports efforts to ensure that all individuals have access to fibre-rich foods as well as efforts to modify individual dietary intake behavior.

Even though the model's inputs were derived from published, peer-reviewed studies, there is always some amount of uncertainty around model inputs $[17,18]$; we have tried to address uncertainty through sensitivity analyses when possible. For example, misclassification, misdiagnosis, and failure to diagnose (as not all individuals who suffer from constipation seek medical care) have hampered efforts to ascertain accurate prevalence and incidence of functional constipation. Even when validated surveys have been used to define constipation, the estimates can differ greatly based on the method used and whether frequency, consistency, or a combination of the two are considered [26]. The diagnostic criteria for constipation have also changed over time, and dietary fibre intake estimates are based on self-report. By using a fairly strict criterion for constipation, the findings presented in the current study may underestimate the number of potential patients and thus the estimated cost savings. However, sensitivity analyses were conducted that varied the prevalence of constipation and thus help provide minimum and maximum results given different inputs.

Also important to considering the broader applicability of these findings, for every input parameter possible, the model attempts to limit values to functional constipation and exclude inputs relevant to IBS. Prevalence estimates are specific to functional constipation, cost studies that included patients with IBS were excluded, and, by design, the model is only relevant for a population for whom increased fibre intake would be expected to minimize constipation. The effect of increasing fibre among patients with IBS could accomplish the opposite. The burden and costs of IBS are substantial $[36,37]$; this model explicitly excludes patients and costs of IBS.

Certain populations are often excluded from the types of surveys that estimate prevalence, including the institutionalized elderly and neonates, as well as patients who are suffering from opioid- or other druginduced constipation or for patients where polypharmacy is necessary [38-40]. These types of patients were specifically excluded from the model.
While the relationship between fibre intake and constipation may be different for these patients, it should be cautioned that they still incur constipationrelated treatment costs. Prevalence, effectiveness, and costs may be different among the institutionalized elderly than in community-dwelling adults, and treatment patterns in the pediatric population are different from those among adults; as a result, the estimates reported are not generalizable to these specific populations.

The estimate used for the decrease in constipation associated with each $1 \mathrm{~g} /$ day increase in dietary fibre intake was derived from a single study of adult women in the United States [29]. Future research to refine the value or to provide separate estimates by age, sex, and country would be welcomed.

Population-level assumptions were made about the association between baseline dietary fibre intake and constipation prevalence. The model does not consider the distribution of intake and how that could affect the proportion of patients who would benefit from particular intake increases; this is due partly to the lack of complete data on population intake of dietary fibre. In reality, there may be adults with a daily intake just below the recommended amount who would benefit from as little as $1 \mathrm{~g}$ additional daily, while there are also adults whose intake is so low that even an increase of $11 \mathrm{~g}$ daily would not be sufficient to eliminate the possibility of low fibre-related constipation. While the model could have considered various distributions of intake in the population, without sufficient data to inform which distributions should be used, the inclusion of this element would have added precision to the model without necessarily increasing accuracy. Based on stool weight, an average increase of $8 \mathrm{~g} / \mathrm{day}$ of wheat bran fibre may be sufficient, on average [41]. Further understanding of the distribution of fibre intake may help refine the model. While it is not the intent of the model to demonstrate cost savings associated with other digestive symptoms, increased intake of fibre has been shown to improve other aspects of bowel function [13] and could be fully explored if more data were available.

The simplifying assumption about the distribution of intake in the model is relevant for the likely changes in constipation prevalence and costs. Specifically, considering the population as a whole, the model assumes that the relationship between constipation prevalence and costs is linear (i.e., that a $1.9 \%$ decrease in constipation would result in a $1.9 \%$ reduction in constipation-related costs). Although 
plausible, this assumption does not account for a variety of scenarios. For instance, this change in constipation might result in patients using prescription medications who were able to switch to over-thecounter (OTC) treatments or it may mean an individual who had previously been using OTC treatments often will now use them only rarely. This change might also mean those with already close-to-acceptable dietary fibre intake might have no constipation-related costs at all. More likely it means a combination of these possibilities will exist in the population rather than just one. Additionally complicating the assignment of costs is that cost estimates are sparse and limited to direct medical costs, without consideration of indirect costs such as those related to lost work or school days per month [42, 43]. In addition, hospital and emergency costs may be incurred; a recent report suggests that hospitalization costs associated with constipation may be considerable and may be comprised substantially of emergency care, although the analysis did not mirror the population in this model and therefore is not directly comparable [44]. Hence, limiting the model to direct medical cost savings driven by outpatient care likely yields a conservative estimate for constipation-related costs. One might argue that there may be some amount of self-medicating with OTC medications among patients who would not qualify as having functional constipation based on survey or clinical criteria. While this may be true, costs for these patients are not borne by the healthcare system and therefore are beyond the scope of the present study.

Many studies on the cost of constipation in the peerreviewed literature focus only on constipation associated with IBS. Since treatment costs for IBSrelated constipation are not a proxy for functional constipation, these studies and their cost estimates were not used in the model. Direct medical costs were also the only estimates considered, therefore yielding a conservative cost savings due to the exclusion of costs associated with lost productivity. Further, the model assumes that patients who present for treatment receive standard therapies. A multitude of alternative, complementary, and newer treatments, however, may have different costs and effectiveness rates [45-47]. The model can be adapted to accommodate data on other treatments as they become available, but they are not included at this point.

Despite these limitations, the model addresses a potential reduction in constipation-related health care costs given the available data, and sensitivity analyses identify the input parameters to which the model is most sensitive.
An important consideration from an economic standpoint relates to the types of foods that individuals would consume to obtain additional dietary fibre in their diets. This analysis did not assume an additional cost for increased dietary fibre consumption. Many foods that are available in both conventional and fibreenriched versions are comparably priced; in addition, there is a lack of data showing that fibre-rich foods are more expensive than lower-fibre foods [48]. Therefore, an additional cost was considered unnecessary for the model. In other words, the model assumes that consumers make simple substitutions of one product for another similarly-priced product that is otherwise nutritionally similar. This is supported by findings from a recent study that demonstrated how fibre intakes can be increased with simple, small-step substitutions without affecting caloric intake [49]. Further, the analysis assumed that individuals are increasing fiber intake in a reasonable manner, with care not to increase intake dramatically at once and with attention to adequate hydration. Failure to consider these measures could result in a need for healthcare resource use, counteracting the potentially beneficial effect of increasing fiber intake on constipation.

It is possible that consumers may replace caloriedense food items with low energy-dense food items. In this case, dietary fibre intake is not the only factor that changes, but intakes of total energy and saturated fat may decrease, while intakes of other dietary components generally found in fibre-rich foods may increase [41]. Overall diet quality may therefore improve as a result of replacing calorie-dense foods items with lower energy-dense, fibre-rich food items $[50,51]$. Thus, it is possible that unintended health and economic consequences of modifying fibre intake may occur. A substitution of a similar product might yield results such as this model calculated; in contrast, the replacement of one type of food for a dissimilar one may mean this model, which focuses only on constipation, grossly underestimates savings in direct medical costs that result from the unintended consequence of eliminating other products from the diet in favor of fibre.

\section{CONCLUSION}

Functional constipation, although not life threatening is a chronic condition that affects quality of life for many Europeans who are otherwise healthy. The public health implications of increasing dietary fibre intake to recommended levels for gastrointestinal health and chronic disease prevention may be considerable. While the vast majority of adults in Europe are not meeting recommendations, the potential benefits of increasing 
intakes for both public health and cost savings are substantial. These efforts should include strategies to increase the supply, availability, and consumer demand of fibre-rich foods and higher fibre varieties of the foods individuals are already consuming.

\section{COMPETING INTERESTS}

This research was commissioned and financially supported by Kellogg Europe Trading Ltd. However, the research and analysis was conducted independently by Exponent, Inc. Jordana Schmier, Vanessa Perez, and Carolyn Hulme-Lowe were employed at Exponent, Inc. during the development of this project and manuscript. At the time of writing this paper, Susan Cloran was employed by Kellogg Europe Trading Ltd, and Kathryn O'Sullivan was a consultant to Kellogg Company.

\section{REFERENCES}

[1] Drossman DA. The functional gastrointestinal disorders and the Rome III process. Gastroenterology 2006; 130(5): 137790. http://dx.doi.org/10.1053/i.gastro.2006.03.008

[2] Mugie SM, Benninga MA, Di Lorenzo C. Epidemiology of constipation in children and adults: a systematic review. Best Pract Res Clin Gastroenterol 2011; 25(1): 3-18. http://dx.doi.org/10.1016/j.bpg.2010.12.010

[3] Peppas G, Alexiou VG, Mourtzoukou E, Falagas ME. Epidemiology of constipation in Europe and Oceania: a systematic review. BMC Gastroenterol 2008; 8: 5. http://dx.doi.org/10.1186/1471-230X-8-5

[4] Schmidt FM, Santos VL. Prevalence of constipation in the general adult population: an integrative review. Wound Ostomy Continence Nurs 2014; 41(1): 70-6; quiz E1-2.

[5] Pinto Sanchez MI, Bercik P. Epidemiology and burden of chronic constipation. Canadian journal of gastroenterology = Journal canadien de gastroenterologie 2011; 25 Suppl B: 11B-5B.

[6] Friedenberg FK, Dadabhai A, Palit A, Sankineni A. The impact of functional constipation on quality of life of middleaged Black Americans: a prospective case-control study. Qual Life Res 2012; 21(10): 1713-7. http://dx.doi.org/10.1007/s11136-011-0089-z

[7] Dennison C, Prasad M, Lloyd A, Bhattacharyya SK, Dhawan $\mathrm{R}$, Coyne K. The health-related quality of life and economic burden of constipation. Pharmacoeconomics 2005; 23(5): 461-76.

http://dx.doi.org/10.2165/00019053-200523050-00006

[8] Sun SX, Dibonaventura M, Purayidathil FW, Wagner JS, Dabbous O, Mody R. Impact of chronic constipation on health-related quality of life, work productivity, and healthcare resource use: an analysis of the National Health and Wellness Survey. Dig Dis Sci 2011; 56(9): 2688-95. http://dx.doi.org/10.1007/s10620-011-1639-5

[9] Ostaszkiewicz J, Hornby L, Millar L, Ockerby C. The effects of conservative treatment for constipation on symptom severity and quality of life in community-dwelling adults. Wound Ostomy Continence Nurs 2010; 37(2): 193-8. http://dx.doi.org/10.1097/WON.0b013e3181cf7206

[10] Neri L, Basilisco G, Corazziari E, Stanghellini V, Bassotti G, Bellini $\mathrm{M}$, et al. Constipation severity is associated with productivity losses and healthcare utilization in patients with chronic constipation. United European Gastroenterol J 2014; 2(2): 138-47.

http://dx.doi.org/10.1177/2050640614528175

[11] Bongers ME, Benninga MA, Maurice-Stam H, Grootenhuis MA. Health-related quality of life in young adults with symptoms of constipation continuing from childhood into adulthood. Health Qual Life Outcomes 2009; 7: 20. http://dx.doi.org/10.1186/1477-7525-7-20

[12] Galvez C, Garrigues V, Ortiz V, Ponce M, Nos P, Ponce J. Healthcare seeking for constipation: a population-based survey in the Mediterranean area of Spain. Aliment Pharmacol Ther 2006; 24(2): 421-8. http://dx.doi.org/10.1111/j.1365-2036.2006.02981.x

[13] Lawton CL, Walton J, Hoyland A, Howarth E, Allan P, Chesters $D$, et al. Short term (14 days) consumption of insoluble wheat bran fibre-containing breakfast cereals improves subjective digestive feelings, general wellbeing and bowel function in a dose dependent manner. Nutrients 2013; 5(4): 1436-55. http://dx.doi.org/10.3390/nu5041436

[14] O'Sullivan K. The superior benefits of wheat bran fibre in digestive health. European Gastroenterology \& Hepatology Review 2012; 8(2): 90-3.

[15] Schmier JK, Miller PE, Levine JA, Perez V, Maki KC, Rains $\mathrm{TM}$, et al. Cost savings of reduced constipation rates attributed to increased dietary fiber intakes: a decisionanalytic model. BMC Public Health 2014; 14(1): 374. http://dx.doi.org/10.1186/1471-2458-14-374

[16] European Food Safety Authority. Scientific Opinion on Dietary Reference Values for carbohydrates and dietary fibre. EFSA Journal 2010; 8(3): 1462.

[17] Caro JJ, Briggs AH, Siebert U, Kuntz KM, Force I-SMGRPT. Modeling good research practices--overview: a report of the ISPOR-SMDM Modeling Good Research Practices Task Force--1. Value in health: the journal of the International Society for Pharmacoeconomics and Outcomes Research 2012; 15(6): 796-803.

http://dx.doi.org/10.1016/j.jval.2012.06.012

[18] Caro JJ, Briggs AH, Siebert U, Kuntz KM, Force I-SMGRPT. Modeling good research practices--overview: a report of the ISPOR-SMDM Modeling Good Research Practices Task Force-1. Medical decision making: an international journal of the Society for Medical Decision Making 2012; 32(5): 667-77. http://dx.doi.org/10.1177/0272989X12454577

[19] Liem O, Harman J, Benninga M, Kelleher K, Mousa H, Di Lorenzo C. Health utilization and cost impact of childhood constipation in the United States. J Pediatr 2009; 154(2): 258-62.

http://dx.doi.org/10.1016/j.jpeds.2008.07.060

[20] Tabbers MM, Dilorenzo C, Berger MY, Faure C, Langendam MW, Nurko S, et al. Evaluation and treatment of functional constipation in infants and children: Evidence-based recommendations from ESPGHAN and NASPGHAN. J Pediatr Gastroenterol Nutr 2014; 58(2): 265-81. http://dx.doi.org/10.1097/MPG.0000000000000266

[21] Index_Mundi. Ireland Demographics Profile 2013. Available at http: //www.indexmundi.com/ireland/demographics_profile. html 2013 [cited 2014 June 18].

[22] Index_Mundi. Spain Demographics Profile 2013. Available at http: //www.indexmundi.com/spain/demographics_profile.htm 2013 [cited 2014 June 18].

[23] Index_Mundi. United Kingdom Demographics Profile 2013. Available at http: //www.indexmundi.com/united_kingdom/ demographics_profile.html 2013 [cited 2014 June 18].

[24] Galvin MA, Kiely M, Harrington KE, Robson PJ, Moore R, Flynn A. The North/South Ireland Food Consumption Survey: the dietary fibre intake of Irish adults. Public Health Nutr 2001; 4(5A): 1061-8.

http://dx.doi.org/10.1079/PHN2001187 
[25] Ministerio de Sanidad Servicios Sociales e Iguladad. Evaluación Nutricional De La Dieta Española. I Energía Y Macronutrientes. Sobre datos de la Encuesta Nacional de Ingesta Dietética (ENIDE)2011.

[26] Suares NC, Ford AC. Prevalence of, and risk factors for, chronic idiopathic constipation in the community: systematic review and meta-analysis. Am J Gastroenterol 2011; 106(9): 1582-91; quiz 1, 92.

[27] Garrigues V, Galvez C, Ortiz V, Ponce M, Nos P, Ponce J. Prevalence of constipation: agreement among several criteria and evaluation of the diagnostic accuracy of qualifying symptoms and self-reported definition in a population-based survey in Spain. Am J Epidemiol 2004; 159(5): 520-6. http://dx.doi.org/10.1093/aje/kwh072

[28] Voderholzer WA, Schatke W, Muhldorfer BE, Klauser AG, Birkner B, Muller-Lissner SA. Clinical response to dietary fiber treatment of chronic constipation. Am J Gastroenterol 1997; 92(1): 95-8.

[29] Dukas L, Willett WC, Giovannucci EL. Association between physical activity, fiber intake, and other lifestyle variables and constipation in a study of women. Am J Gastroenterol 2003; 98(8): 1790-6.

http://dx.doi.org/10.1111/j.1572-0241.2003.07591.x

[30] Christie AH, Culbert P, Guest JF. Economic impact of low dose polyethylene glycol 3350 plus electrolytes compared with lactulose in the management of idiopathic constipation in the UK. Pharmacoeconomics 2002; 20(1): 49-60. http://dx.doi.org/10.2165/00019053-200220010-00005

[31] Guest JF, Varney SJ. Pharmacoeconomic impact of lowdose macrogol 3350 plus electrolytes compared with lactulose in the management of chronic idiopathic constipation among ambulant patients in Belgium. Clin Drug Investig 2004; 24(12): 719-29. http://dx.doi.org/10.2165/00044011-200424120-00003

[32] Guest JF, Clegg JP, Helter MT. Cost-effectiveness of macrogol 4000 compared to lactulose in the treatment of chronic functional constipation in the UK. Curr Med Res Opin 2008; 24(7): 1841-52. http://dx.doi.org/10.1185/03007990802102349

[33] Taylor RR, Guest JF. The cost-effectiveness of macrogol 3350 compared to lactulose in the treatment of adults suffering from chronic constipation in the UK. Aliment Pharmacol Ther 2010; 31(2): 302-12.

[34] World Gastroenterology Organisation Global Guidelines. Constipation: a global perspective. Available at http: //www.worldgastroenterology.org/assets/export/userfiles/05_ constipation.pdf 2010.

[35] American Gastroenterological Association, Bharucha AE, Dorn SD, Lembo A, Pressman A. American Gastroenterological Association medical position statement on constipation. Gastroenterology 2013; 144(1): 211-7. http://dx.doi.org/10.1053/j.gastro.2012.10.029

[36] Dibonaventura MD, Prior M, Prieto P, Fortea J. Burden of constipation-predominant irritable bowel syndrome (IBS-C) in France, Italy, and the United Kingdom. Clin Exp Gastroenterol 2012; 5: 203-12.

http://dx.doi.org/10.2147/CEG.S35568

[37] Fortea J, Prior M. Irritable bowel syndrome with constipation: a European-focused systematic literature review of disease burden. J Med Econ 2013; 16(3): 329-41.

http://dx.doi.org/10.3111/13696998.2012.756397
[38] Frank L, Schmier J, Kleinman L, Siddique R, Beck C, Schnelle $\mathrm{J}$, et al. Time and economic cost of constipation care in nursing homes. J Am Med Dir Assoc 2002; 3(4): 21523.

http://dx.doi.org/10.1016/S1525-8610(04)70481-8

[39] Saps M, Sztainberg M, Di Lorenzo C. A prospective community-based study of gastroenterological symptoms in school-age children. J Pediatr Gastroenterol Nutr 2006; 43(4): 477-82.

http://dx.doi.org/10.1097/01.mpg.0000235979.41947.f6

[40] Uc A, Hyman PE, Walker LS. Functional gastrointestinal disorders in African American children in primary care. $\mathrm{J}$ Pediatr Gastroenterol Nutr 2006; 42(3): 270-4. http://dx.doi.org/10.1097/01.mpg.0000189371.29911.68

[41] Stevenson L, Philips F, O'Sullivan K, Walton J. Wheat bran: its composition and benefits to health, a European perspective. Int J Food Sci Nutr 2012; 63(8): 1001-3.

[42] Johanson JF, Kralstein J. Chronic constipation: a survey of the patient perspective. Aliment Pharmacol Ther 2007; 25(5): 599-608. http://dx.doi.org/10.1111/j.1365-2036.2006.03238.x

[43] McClung HJ, Boyne L, Heitlinger L. Constipation and dietary fiber intake in children. Pediatrics 1995; 96(5 Pt 2): 999-1000.

[44] Hospital Episode Statistics, Admitted Patient Care, England 2012-13 [NS] [Internet] 2013. Available from: http: //www.hscic.gov.uk/catalogue/PUB12566.

[45] Woodward S, Norton C, Barriball KL. A pilot study of the effectiveness of reflexology in treating idiopathic constipation in women. Complement Ther Clin Pract 2010; 16(1): 41-6. http://dx.doi.org/10.1016/j.ctcp.2009.06.002

[46] van Tilburg MA, Palsson OS, Levy RL, Feld AD, Turner MJ, Drossman DA, et al. Complementary and alternative medicine use and cost in functional bowel disorders: a six month prospective study in a large HMO. BMC Complement Altern Med 2008; 8: 46. http://dx.doi.org/10.1186/1472-6882-8-46

[47] Cheng CW, Bian ZX, Wu TX. Systematic review of Chinese herbal medicine for functional constipation. World $\mathrm{J}$ Gastroenterol 2009; 15(39): 4886-95. http://dx.doi.org/10.3748/wig. 15.4886

[48] Crowe FL, Appleby PN, Allen NE, Key TJ. Diet and risk of diverticular disease in Oxford cohort of European Prospective Investigation into Cancer and Nutrition (EPIC): prospective study of British vegetarians and non-vegetarians. BMJ 2011; 343: d4131. http://dx.doi.org/10.1136/bmj.d4131

[49] Hornick B, Birkett A, DeAnn L. The fiber deficit, part 3beyond traditional fiber sources: The role of adding fiber to food in improving fiber intakes. Nutrition Today 2013; 48(4): 168-73.

http://dx.doi.org/10.1097/NT.0b013e31829da149

[50] Marquart L, Wiemer KL, Jones JM, Jacob B. Whole grains health claims in the USA and other efforts to increase wholegrain consumption. Proc Nutr Soc 2003; 62(1): 151-60. http://dx.doi.org/10.1079/PNS2003242

[51] Aldoori WH, Giovannucci EL, Rockett HR, Sampson L, Rimm EB, Willett WC. A prospective study of dietary fiber types and symptomatic diverticular disease in men. J Nutr 1998; 128(4): 714-9.

Received on 10-11-2014

\section{DOI: http://dx.doi.org/10.6000/1927-5951.2015.05.01.3}

\section{(C) 2015 Schmier et al.; Licensee Lifescience Global.}

This is an open access article licensed under the terms of the Creative Commons Attribution Non-Commercial License (http://creativecommons.org/licenses/by-nc/3.0/) which permits unrestricted, non-commercial use, distribution and reproduction in any medium, provided the work is properly cited. 